\title{
OCORRÊNCIA DE NANISMO EM PLANTA DE TOMATEIRO DO TIPO GRAPE ${ }^{1}$
}

\author{
GABRIEL MASCARENHAS MACIEL ${ }^{2 *}$, ERNANI CLARETE DA SILVA ${ }^{3}$, \\ MARCO AURÉLIO ROCHA FERNANDES ${ }^{2}$
}

\begin{abstract}
RESUMO - O conhecimento genético de manifestações fenotípicas de características de importância agronômica em vegetais é uma atividade de grande importância, cujos resultados são amplamente utilizados por fitomelhoristas. O objetivo do presente trabalho foi estudar o tipo de segregação genética que ocorre ao se cruzar um genótipo anão versus genótipo de hábito de crescimento indeterminado. A referida planta foi encontrada vegetando espontaneamente no município de Piracicaba (SP) em local de descarte de frutos por tomaticultores juntamente com as plantas normais. As sementes de ambas as plantas foram colhidas separadamente para início do estudo e codificadas da seguinte forma: planta com fenótipo normal (FN) e planta com fenótipo atípico com características de porte anão (FA). A metodologia constou de cruzamentos biparentais recíprocos e retrocruzamentos da geração $\mathrm{F}_{1}$ com o genitor $\mathrm{FA}$ e obtenção de geração $\mathrm{F}_{2}$. Os dados obtidos oriundos da contagem de plantas das populações obtidas $\left(\mathrm{F}_{1}, \mathrm{~F}_{2}\right.$ e $\left.\mathrm{F}_{1} \mathrm{RC}_{1}\right)$ foram submetidos ao teste de $\chi^{2}$ de acordo com a frequência esperada e observada do fenótipo normal (FN) e planta com fenótipo atípico com características de porte anão (FA), tendo como hipótese uma segregação mendeliana 3:1, obtida para herança monogênica. Pelos resultados obtidos foi possível concluir que o fenótipo observado na planta no presente estudo é de origem genética recessiva, podendo ser transmito para outras plantas via cruzamento.
\end{abstract}

Palavras-chave: Solanum lycopersicum L. Gene $d$ (Dwarf). Herança. Alelo. Mutação.

\section{DWARFISM OCCURRENCE IN TOMATO PLANT TYPE GRAPE}

\begin{abstract}
The phenotypic manifestations of genetic knowledge of important agronomic traits in plants is an activity of great importance, whose results are widely used in plant breeding. The objective was to study the type of genetic segregation that occurs when crossing a dwarf genotype versus indeterminate growth habit genotype. Their plant was found growing spontaneously in Piracicaba (SP), on-site disposal of fruits per tomatoes producers along with normal plants. Seeds of both plants were harvested separately for baseline and coded as follows: a plant with a normal phenotype (FN) and plant with atypical phenotype with characteristics of dwarfism (FA). The methodology consisted of biparental and reciprocal backcrosses of the $F_{1}$ to the parent FA and obtained the $\mathrm{F}_{2}$ generation. The data derived from the plant count populations obtained $\left(\mathrm{F}_{1}, \mathrm{~F}_{2}\right.$ and backcrosses $)$ were tested using the $\chi^{2}$ according to the expected frequency and observed the normal phenotype (FN) and plant with atypical phenotype with characteristics of dwarfism (FA), under the hypothesis Mendelian segregation 3:1, obtained by monogenic inheritance. From the results, it can be concluded that the phenotype observed in the plant in this study is recessive genetic origin can be inserted into other plants by crossing.
\end{abstract}

Keywords: Solanum lycopersicum L. Gene d (Dwarf). Inheritance. Allele. Mutation.

\footnotetext{
*Autor para correspondência

${ }^{1}$ Recebido para publicação em 08/08/2014; aceito em 31/08/2015

${ }^{2}$ Instituto de Ciências Agrárias, UFU, Rodovia LMG 746, KM01, 38500-000, Monte Carmelo (MG); gabrielmaciel@iciag.ufu.br.

${ }^{3}$ Departamento de Ciências Agrárias, UFSJ, Caixa postal 56, 35701-970, Sete Lagoas (MG).
} 


\section{INTRODUÇ̃̃̃}

O tomateiro (Solanum lycopersicum L.) está entre as hortaliças de maior importância econômica (FILGUEIRA, 2008). O valor total do mercado de sementes de tomate do tipo grape alcançou R\$ 2.883.800,00 em 2012, sendo estes cultivados em mais de 327,70 hectares (ABCSEM, 2011).

Além do importante aspecto socioeconômico, a referida espécie é rotineiramente utilizada em pesquisas na área de genética vegetal em função da disponibilidade de mutantes (ZSOGON et al., 2008; CAMPOS et al., 2009; LIMA et al., 2009). As variações genéticas naturais em tomateiros assumem grande importância e vêm sendo usadas intensivamente, como é o caso das mutações jointless (MAO et al., 2000) e self-pruning (PIOTTO; PERES, 2012).

Filgueira (2008) já classificava o tomateiro como uma planta tipicamente perene, de hábito de crescimento indeterminado ou determinado e usado extensivamente nos programas de melhoramento para tomateiro do tipo industrial e in natura. Antes da ocorrência de mutação as cultivares de tomateiro eram de crescimento indeterminado, condicionado pelo alelo dominante Self-Pruning $(S P)$ para o lócus em questão. Posteriormente, a mutação $s p$ foi mapeada no cromossomo seis, cujo alelo em homozigose recessiva provoca a "auto-poda" (self-pruning), ou seja, a perda da capacidade de continuar formando ramos vegetativos após o florescimento (PIOTTO; PERES, 2012).

Com relação ao desenvolvimento vegetativo e hábito de crescimento, o gene $d$ (Dwarf) que condiciona plantas de crescimento do tipo anão pode assumir grande importância no desenvolvimento de cultivares modernas de tomateiro. Pesquisadores têm utilizado cultivares miniatura, porém de frutos redondos, denominada Mini-Tom (MT), como modelo genético para estudos básicos, genéticos e fisiológicos (WANG et al., 2005; WATANABE et al., 2007; SILVA et al., 2011; MONTEIRO et al., 2012; PÉREZ; AHMED, CABEZAS, 2013). No entanto, pouco se sabe a respeito do tipo de herança condicionado pelas plantas anãs ao cruzar com plantas de hábito de crescimento indeterminado. No Brasil, não estão disponíveis linhagens de tomateiro do tipo grape, com ${ }^{\circ}$ Brix elevado, portadoras do gene $(d)$ Dwarf, para uso direto no melhoramento genético. Assim, do mesmo modo que fitomelhoristas têm explorado o potencial heterótico proporcionado por parentais contrastantes quanto ao hábito de crescimento em tomateiro (determinado versus indeterminado) (NIZIO et al., 2008; ANDRADE et al., 2014), faz-se necessário um estudo prévio do tipo de herança para o caráter anão para que seja possível realizar a mes- ma estratégia utilizando linhagens anãs. O estudo da herança de características de relevância agronômica em vegetais é uma atividade de grande importância, cujos resultados são amplamente utilizados pelos fitomelhoristas (MACIEL; SILVA, 2008). O conhecimento do número de genes envolvidos em determinado caráter, a sua localização no cromossomo, bem como a sua maneira de interagir permitem construir mapas cromossômicos, determinar o critério e a intensidade da seleção, método de condução de populações segregantes, assim como determinar ideótipos de plantas com características desejáveis (BUENO; MENDES, CARVALHO, 2006).

Assim, objetivou-se com este trabalho estudar o tipo de segregação genética que ocorre ao se cruzar um genótipo anão versus genótipo de hábito de crescimento indeterminado.

\section{MATERIAL E MÉTODOS}

O trabalho foi conduzido nas dependências da Universidade Federal de Uberlândia, Campus Monte Carmelo, no período de janeiro de 2012 a julho de 2013. Foram utilizados dois genótipos de tomateiro do tipo grape, encontrados vegetando espontaneamente no município de Piracicaba (SP) em local de descarte de frutos por tomaticultores. As plantas que apresentavam fenótipo tipo anão e normal (Figura 1) foram transplantadas para vasos de cinco litros preenchidos com substrato comercial a base de fibra de coco e cultivadas até a fase de produção e colheita das sementes.

Todo germoplasma coletado vem sendo mantido e identificado pelo Laboratório de Análise de Sementes e Recursos Genéticos (LAGEN) situado na Universidade Federal de Uberlândia, Campus Monte Carmelo. As plantas em plena produção de frutos apresentaram fenótipos distintos e contrastantes. O fenótipo anão se caracterizou por uma planta atípica, com altura aproximada de $30,0 \mathrm{~cm}$, hábito de crescimento indeterminado (apresentando morfologicamente uma inflorescência após três folhas) e folhas espessas de coloração verde escuro. Os frutos são vermelhos, tipo grape sem ombro verde, pesando em média $10 \mathrm{~g}$. As plantas com fenótipo normal apresentaram hábito de crescimento indeterminado com frutos vermelhos, tipo grape sem ombro verde. Para obtenção das sementes, as plantas foram conduzidas e mantidas em ambiente protegido.

Sementes de ambas as plantas foram colhidas separadamente para início do estudo e codificadas da seguinte forma: planta com fenótipo normal (FN) e planta com fenótipo atípico com características de porte anão (FA). 


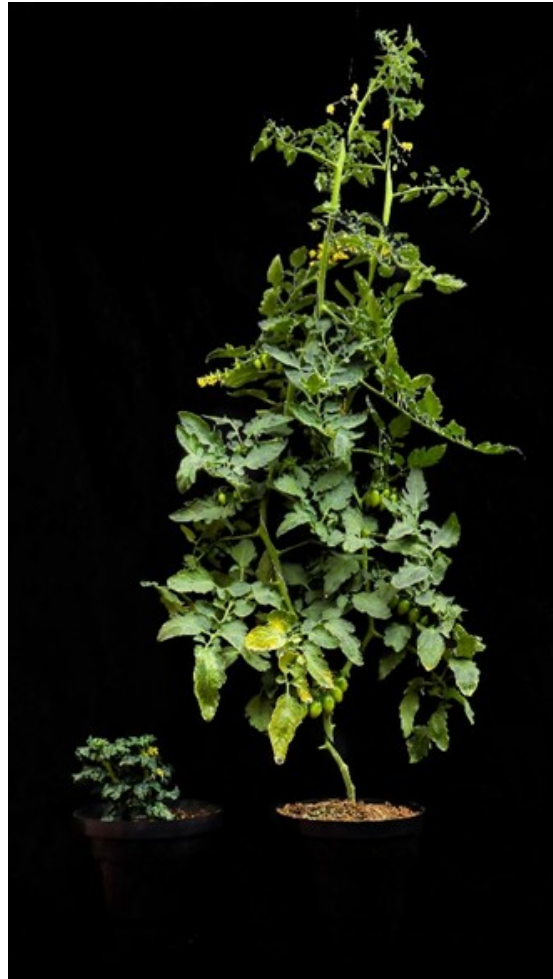

Figura 1. Parentais envolvidos no estudo FA (fenótipo anão, a esquerda) e FN (fenótipo normal com hábito de crescimento indeterminado, a direita).

A metodologia utilizada constou de cruzamentos biparentais recíprocos e retrocruzamentos da geração $\mathrm{F}_{1}$ com o genitor $\mathrm{FA}$ e foi dividida em etapas distintas. Na primeira etapa foi avaliada a homozigose dos genitores (FA e FN) e, simultaneamente, efetuados os cruzamentos biparentais [(FA versus FN) e (FN versus FA)]. Mudas de ambos os parentais foram obtidas em bandejas de poliestireno de 200 células preenchidas com substrato comercial a base de fibra de coco. Quando as mudas atingiram quatro folhas definitivas foram transplantadas para vasos de cinco litros e mantidos em casa-devegetação. As plantas foram conduzidas com apenas uma haste e tutoradas verticalmente, dispensando-se o tutoramento do parental FA devido ao seu porte reduzido, plantas firmes e eretas. Todos os tratos culturais e fitossanitários foram realizados de acordo com o preconizado para a cultura do tomateiro (FILGUEIRA, 2008).

Para essa primeira etapa foram conduzidas 75 plantas de cada parental (FA e FN). Quando as plantas iniciaram o florescimento, aproximadamente aos 75 dias após semeadura (DAS), foram selecionadas as três plantas mais sadias e vigorosas de cada genitor. Nos ramos florais (cacho) dessas plantas foi realizada antes da antese a emasculação dos três primeiros botões florais. As flores não emasculadas foram eliminadas para evitar possível contaminação com eventual transferência de pólen. A operação foi realizada em ambos os genitores de maneira a permitir os cruzamentos recíprocos. Utilizando-se um vibrador manual, foi retirado o pólen de flores completamente abertas de ambos os parentais. Os grãos-de-pólen foram colocados em cápsulas de sílica-gel devidamente identificadas e utilizados para polinização das flores emasculadas no mesmo dia. As flores emasculadas e polinizadas foram identificadas com lã vermelha e posteriormente as sementes colhidas desses frutos quando maduros. A homozigose dos genitores quanto ao hábito de crescimento também foi avaliada observando-se o fenótipo de cada uma das 75 plantas referente a cada parental (FA e FN) expressados fenotipicamente conforme Figura 1.

A segunda etapa consistiu no semeio das sementes $\mathrm{F}_{1}$ dos cruzamentos recíprocos [(FA versus FN) e (FN versus FA)] e dos parentais (FA e FN). Após a obtenção de uma população com 100 plantas $\mathrm{F}_{1}$ (50 plantas de cada cruzamento recíproco) e 30 plantas de cada parental, os fenótipos (FA e FN) foram avaliados na população $F_{1}$, ao mesmo tempo em que os retrocruzamentos $F_{1}$ versus parental FA foram realizados. Todos os cuidados de condução da cultura e cruzamentos observados na etapa anterior foram executados também nessa etapa. Sementes $F_{2}$ oriundas de autofecundação de plantas $F_{1}$ e sementes dos retrocruzamento $\left(\mathrm{F}_{1}\right.$ versus $\left.\mathrm{FA}\right)$ foram colhidas, constituindo assim material para a terceira etapa do trabalho.

$\mathrm{Na}$ terceira etapa foi realizado a semeadura dos genótipos obtidos na etapa anterior $\left(\mathrm{F}_{2}\right.$ e $\mathrm{F}_{1}$ versus FA). Em duas casas-de-vegetação foram constituídas uma população de 59 plantas da geração $F_{2}$ (segregante) e 110 plantas oriundas de sementes do retrocruzamento ( $F_{1}$ versus $\left.F A\right)$. Nas populações $F_{2} e$ de retrocruzamento $\left(\mathrm{F}_{1}\right.$ versus $\left.\mathrm{FA}\right)$ as plantas foram contadas e separadas de acordo com a expressão 
fenotípica em estudo (Figura 1). Em seguida, os dados foram submetidos ao teste de $\chi^{2}$, a $5 \%$ de probabilidade, de acordo com a frequência esperada e observada do fenótipo normal (FN) e do fenótipo atípico com características de porte anão (FA), tendo como hipótese uma segregação mendeliana 3:1, obtida para herança monogênica. O qui-quadrado calculado foi estimado por meio da expressão:

$$
x_{c}^{2}=\sum_{i=1}^{k} \frac{\left(O_{i}-E_{i}\right)^{2}}{E_{i}}
$$

em que: $\mathrm{O}_{\mathrm{i}}$ é o número observado de indivíduos na iésima classe fenotípica; $\mathrm{E}_{\mathrm{i}} \mathrm{o}$ número esperado de indivíduos na i-ésima classe fenotípica; e k o número de classes fenotípicas.

\section{RESULTADOS E DISCUSSÃO}

Os genitores utilizados no cruzamento foram fenotipicamente homozigotos para a característica avaliada (FA e FN), uma vez que não foi observada segregação após as autofecundações (Tabela 1). Todas as plantas originadas de FA mantiveram o fenótipo anormal caracterizado pelo porte anão, enquanto que o parental de FN manteve o mesmo fenótipo. Observou-se também dominância completa do fenótipo FN sobre $F A$, já que na geração $F_{1}$ todas as plantas expressaram fenótipos normais (FN) independente da direção do cruzamento (Tabela 1). Na geração $\mathrm{F}_{2}$, os valores absolutos indicaram uma segregação cuja proporção aproximou-se de 3:1, uma vez que ocorreram 49 plantas do tipo FN e 10 plantas do tipo FA (Tabela 1). De modo semelhante, no cruzamento teste $\left(\mathrm{F}_{1}\right.$ versus $\left.\mathrm{FA}\right), 53$ plantas expressaram FA e 57 plantas expressaram $\mathrm{FN}$, uma proporção próxima de $1: 1$

Tabela 1. Número de plantas de tomateiro tipo grape que apresentaram plantas anãs.

\begin{tabular}{|c|c|c|c|c|c|c|}
\hline \multirow{3}{*}{ Fenótipos } & \multicolumn{4}{|c|}{ Gerações } & \multirow[b]{3}{*}{ F1 1 P1 } & \multirow[b]{3}{*}{ F2 } \\
\hline & \multicolumn{2}{|c|}{ Autofecundação } & \multicolumn{2}{|c|}{ Cruzamentos Recíprocos $\left(\mathrm{F}_{1}\right)$} & & \\
\hline & P1 & $\mathbf{P 2}$ & P1 x P2 & P2 x P1 & & \\
\hline $\mathrm{P} 1=\mathrm{FA}$ & 75 & - & - & - & 53 & 10 \\
\hline $\mathrm{P} 2=\mathrm{FN}$ & - & 75 & 38 & 50 & 57 & 49 \\
\hline Total & 75 & 75 & 38 & 50 & 110 & 59 \\
\hline
\end{tabular}

Quando aplicado o teste de $\chi^{2}$, os desvios entre as frequências observadas (FO) e esperadas (FE) não foram significativos a uma probabilidade maior que $95 \%$, considerando-se a hipótese de segregação $3: 1$, ou seja, três plantas FN para cada planta FA na geração segregante $F_{2}$ (Tabela 2). Diferentes formas e intensidades na expressão do fenótipo tipo anão foram estudadas (WANG et al., 2005; WATANABE et al., 2007). No presente estudo não foi possível comparar esses níveis por não ter sido incluso genótipos conhecidos quanto a referida intensidade estudada, servindo como testemunhas. Portanto, sugerese que o fenótipo anormal (FA) em estudo seja uma manifestação do gene $d$ que condiciona plantas com porte anão. Ademais, é possível afirmar que seja controlado por genes recessivos homozigotos, tornando-se possível explorar em programas de melhoramento genético e em análises dialélicas por se tratar de um parental altamente contrastante. Por outro lado, observou-se segregação para outras características tanto em FA quanto em FN. Esse fato induz supor que as plantas coletadas no local de descarte sejam produtos $\mathrm{F}_{2}$, oriundos de autofecundação de algum híbrido do tipo grape cultivado pelo tomaticultor.

Tabela 2. Teste de $\chi^{2}$ da hipótese para herança monogênica da característica plantas anãs (Dwarf) em tomate tipo grape.

\begin{tabular}{|c|c|c|c|c|c|c|}
\hline \multirow[b]{2}{*}{ Fenótipos } & \multicolumn{3}{|c|}{ Geração $F_{2}$} & \multicolumn{3}{|c|}{ Cruzamento Teste } \\
\hline & FO' $^{1}$ & $\mathrm{FE}^{2}$ & Desvio & $\mathbf{F O}^{1}$ & $\mathbf{F E}^{2}$ & Desvio \\
\hline $\mathrm{P} 1=\mathrm{FA}$ & 10 & 14,75 & $-4,75$ & 53 & 55 & -2 \\
\hline $\mathrm{P} 2=\mathrm{FN}$ & 49 & 44,25 & 4,75 & 57 & 55 & 2 \\
\hline Total & 59 & 59 & $\chi^{2}=2,04^{n s}$ & 110 & 110 & $\chi^{2}=0,82^{n s}$ \\
\hline
\end{tabular}

${ }^{1} \mathrm{FO}=$ Frequência observada; ${ }^{2} \mathrm{FE}=$ Frequência esperada.

Produtores de tomate tipo grape buscam híbridos com internódio curto e alta heterose. A partir do genótipo anão desta pesquisa sugere-se que seja feito combinações híbridas em forma de análise dialélica visando estudos específicos quanto a exploração do potencial dessa linhagem anã como genitora. Devido a baixa produtividade de frutos e consequentemente baixa eficiência na produção de sementes (aproximadamente 3,0 frutos viáveis por planta contendo em média 13,0 sementes por fruto) do genótipo FA sugere-se que este seja utilizado como parental masculino nos dialelos. Plantas homozigotas para o alelo $d$ apresentam tamanho e número de células reduzidas (NADHZIMOV et al., 1988). A assertiva 
permite propor que novos estudos sejam realizados via microscopia eletrônica analisando o tecido vegetal do genótipo anão (FA) obtido neste estudo, visando mais informações a respeito do gene responsável pelo presente controle do fenótipo.

Muitas mutações que causam o nanismo estão envolvidas na percepção do metabolismo da planta ao hormônio giberelina (GA) (REID et al., 1993). Outra forma de expressar mutantes em plantas anãs é através da produção de paredes celulares anormais (REITER; CHAPPLE, SOMERVILLE, 1993) ou defeitos na célula de expansão/alongamento (TAKAHASHI et al., 1995). Ressalta-se no presente estudo que o genótipo anão utilizado não foi obtido via indução por raios gama (MATSUKURA et al., 2007). O genótipo em estudo se trata de uma planta atípica identificada ao acaso em uma população de ocorrência espontânea.

\section{CONCLUSÕES}

Pelos resultados obtidos é possível concluir que o fenótipo observado na planta no presente estudo é de origem genética recessiva, podendo ser transmito para outras plantas via cruzamento.

\section{REFERÊNCIAS}

ABCSEM - Associação Brasileira do Comércio de Sementes e Mudas. Dados do setor Pesquisa de mercado de sementes de hortaliças. 2011. Disponível em: http://www.abcsem.com.br/ dadosdosegmento.php. Acesso em: 25 jul. 2014.

ANDRADE, M. C. et al. Capacidade combinatória de linhagens de tomateiro em híbridos do tipo italiano. Bragantia, Campinas, v. 73 , n. 3, p. 237-245, 2014.

BUENO, L. C. S.; MENDES, A. N. G.; CARVALHO, S. P. Melhoramento Genético de Plantas: princípios e procedimentos. 2 ed. Lavras, MG: UFLA, 2006. 319 p.

CAMPOS, M. L. et al. Brassinosteroids interact negatively with jasmonates in the formation of antiherbivory traits in tomato. Journal of Experimental Botany, Piracicaba, v. 60, n. 15, p. 4347-4361, 2009.

FILGUEIRA, F. A. R. Novo manual de Olericultura: Agrotecnologia moderna na produção e comercialização de hortaliças. 3 ed. Viçosa, MG: UFV, 2008. $421 \mathrm{p}$

LIMA, J. E. et al. Callus, shoot and hairy root formation in vitro as affected by the sensitivity to auxin and ethylene in tomato mutants. Plant Cell Reports,
Piracicaba, v. 28, n. 8, p. 1169-1177, 2009.

MACIEL, G. M.; SILVA, E. C. Herança do formato do fruto em tomateiro do grupo cereja. Horticultura Brasileira, Brasília, v. 26, n. 4, p. 495-498, 2008.

MAO, L. et al. JOINTLESS is a MADS-box gene controlling tomato flower abscission zone development. Nature, Londres, v. 406, n. 6798, p. 910-913, 2000 .

MATSUKURA, C. et al. Generation of gamma irradiation-induced mutant lines of the miniature tomato (Solanum lycopersicum L.) Micro-Tom. Plant Biotechnology, Tokyo, v. 24, n. 1, p. 39-44, 2007.

MONTEIRO C. C. et al. Biochemical and histological characterization of tomato mutants. Anais da Academia Brasileira de Ciências, Rio de Janeiro, v. 84 , n. 2, p. 573-585, 2012.

NADHZIMOV, U. K. et al. Growth and gibberellin relations of the extreme dwarf $\mathrm{dx}$ mutant. Physiologia Plantarum, Copenhagen, v. 73, n. 2, p. 252-256, 1988 .

NIZIO, D. A. C. et al. Caracterização de genótipos de tomateiro resistentes a begomovírus por marcador molecular co-dominante ligado ao gene Ty-1. Pesquisa Agropecuária Brasileira, Brasília, v. 43, n. 12, p. 1699-1705, 2008.

PÉREZ S.; AHMED A. I. S.; CABEZAS D. Molecular and biochemical characterization of tomato (Solanum lycopersicum L.) plants cv. Micro-Tom under lead $(\mathrm{Pb})$-induced stress. Biotecnología Aplicada, La Habana, v. 30, n. 3,p. 194-198, 2013.

PIOTTO, F. A.; PERES, L. E. P. Base genética do hábito de crescimento e florescimento em tomateiro e sua importância na agricultura. Ciência Rural, Santa Maria, v. 42, n. 11, p. 1941-1946, 2012.

REID, J. B. Plant hormone mutants. Journal of Plant Growth Regulation, New York, v. 12, n. 4, p. 207-226, 1993

REITER, W. D.; CHAPPLE, C. C. S.; SOMERVILLE, C. R. Altered growth and cell walls in a fucose-deficient mutant of Arabidopsis. Science, New York, v. 261, n. 5124, p. 1032-1035, 1993.

SILVA, A. C. et al. Root growth of tomato seedlings intensified by humic substances from peat bogs. Revista Brasileira de Ciência do Solo, Viçosa, v. 35, n. 5, p. $1609-1617,2011$

TAKAHASHI, T. et al. The diminuto gene of Arabidopsis is involved in regulating cell elongation. Genes Development, New York, v. 9, n. 1, p. $97-$ 
107, 1995.

WANG, H. et al. The tomato Aux/IAA transcription factor IAA9 is involved in fruit development and leaf morphogenesis. Plant Cell, Rockville, v. 17, n. 10, p. 2676-2692, 2005.

WATANABE, S. et al. Ethylmetha nesulfonate (EMS) mutagenesis of Solanum lycopersicum cv. Micro-Tom for large scale mutant screens. Plant Biotechnology, Tokyo, v. 24, n. 1, p. 33-38, 2007.

ZSOGON, A. et al. Reduced arbuscular mycorrhizal colonization in tomato ethylene mutants. Scientia Agricola, Piracicaba, v. 65, n. 3, p. 259-267, 2008. 